\title{
NATURE
}

\section{Congress and the Prospects for Higher Education}

Is will be a tragedy for higher education in the United States if Congress fails to deal in an enlightened way with the Higher Education Bill (see page 365). For several years, a great many educational institutions in the United States have been driven to penury and even out of existence by the difficulty of keeping in the black. Their problems arise from the simple laws of supply and demand. Under present arrangements, most colleges and universities have to finance their teaching operations from fees collected from students. With inflation as it is, there is no escape from continuing and steep increases of tuition fees, and in the past few years it has become apparent that the student market is by no means inelastic. Many young people are being forced to recognize that tertiary education is beyond their means. The question which Congress has now to decide is not merely that of how best to devise a mechanism for channelling money to the colleges and universities but whether it wishes to see the scale of higher education in the United States determined by the necessarily arbitrary balance which is struck at any time between the level of tuition fees and the capacity of young people and their families to pay them. In a rational world, the Administration would no doubt have put forward proposals for channelling funds to institutions in higher education which are at once less arbitrary than those which Congress is now considering and less obviously designed to satisfy identifiable vested interests, but the great irony of the legislative process is that the Higher Education Bill has been complicated by an attempt to use it as a means of limiting the bus-ing of children from one place to another so as to break down the segregation of minorities in the United States.

The first need is to detach the anti-bus-ing amendment from the provisions of the bill which deal with higher education proper. Understandably, in the past five years, bus-ing amendment with an undertaking to look again at the United States. The proposal that funds for bus-ing should now be taken away quite understandably gives offence to liberal opinion anxious to see a rapid erosion of social barriers in the United States. It is only fair to add that the issue is so controversial that objective studies of its efficacy would be hard to carry out, but with five years of experience as a guide, there is at least a chance that it would now be possible to decide in what circumstances bus-ing is most effective and whether there are some circumstances in which quite different devices would be preferable. So is it entirely beyond the wit of Congress and those who wish to see an improvement of racial relations in the United States to head off the antibus-ing amendment with an undertaking to look again at the working of that programme in the light of the experience of the past five years.

The Higher Education Bill itself is also controversial. Luckily, the provision that students should be given a stipend of up to $\$ 1,400$ a year from federal funds has survived unchanged from last year's Senate Higher Educa- tion Bill-this in itself could do a great deal to permit access to the universities by young men and women from disadvantaged families. And even though there might be advantages in a closer analogy with the British system, in which local authorities are responsible for spending the central government's money on student grants, in the long run the increased demand for higher education which the Educational Opportunity Grants will provide, and the federal vigilance on educational standards that will no doubt follow, will be a great benefit to all colleges and universities.

The difficulty has arisen over the way in which the federal government should spend money on support of institutions. Congress has devised for itself a formula which links the scale of institutional support to the amounts of money paid to students at each institution under the provisions for Educational Opportunity Grants and other grants, with a miniscule recognition of postgraduate teaching thrown in for good measure. By means of this formula, the federal government will be able in future to wash its hands of attempts to distinguish between good colleges and universities and the rest, a matter of great convenience for any Administration. The colleges themselves object to the way in which institutional grants will be weighted by the amounts of money paid out to their more needy students. But is not a better solution the development in the United States of the grant-giving bodies which now adminiser funds for university education in several countries elsewhere-the University Grants Committee in Britain is a good example? From this point of view, if the anti-bus-ing amendment can be detached from the Higher Education Bill, it would be best if Congress were to approve of the chief proposals on financing and were then to resolve that it would spend the next three years working towards a more permanent and satisfactory solution.

\section{Or Ehrlich's Bucklash}

SinCE his publication of The Population Bomb in 1966, Dr Paul Ehrlich has been one of the most constant, though not the most consistent, of the contributors to public discussion of what he calls the prospect of ecocatastrophe. Last week he turned up in Stockholm, a guest of the International Planned Parenthood Federation, to complain about American behaviour in Vietnam, commendably to draw attention to the gap between rich and poor countries, curiously to suggest that "man's assault on the vital systems is now increasing by about five per cent per year" and to plead for population stability. Two weeks earlier, he had identified for the gathering at Harvard to celebrate the centenary of the Arnold Arboretum, what he called an ecological backlash - a supposedly misguided attempt by natural scientists who are not "evolutionary biologists" to minimize predictions of disaster - with the usual proviso 